\title{
ESTUDIOS
}

\section{Normas Periodísticas de José Martí}

\author{
¡Tíne TANTO EL PERIODISTA DE SOLDADO!
}

$\mathrm{E}$ L periodismo fue, en Martí, una derivación del escritor, determinada por las circunstancias. Porque su vocación esencial era la de escritor, junto a la de apóstol, y puede decirse que ambas nacieron a la vez en su espíritu apasionado y desbordante, que fue capaz al mismo tiempo de concebir la redención de su patria por el sacrificio y por la llama del enardecimiento que movería a sus compatriotas para la lucha redentora. Pensemos en una fecha y en un momento en que Martí cumple los dieciséis años. Es el momento en que los ánimos enardecidos de los habaneros no pueden contenerse, y en que la milicia española responde a ese entusiasmo con sus represalias, haciendo victimas aquí y allá, en que ocurren escenas trágicas como las del Palacio de Aldama, la Acera del Louvre y el Teatro de Villanueva. Martí, que se ha formado en la Escuela de Mendive, con la doble formación literaria y cívica, es un estudiante que se destaca entre sus compañeros del Instituto de La Habana, en el grupo de los que simpatizan con Céspedes y hacen versos a su gesta libertadora o critican las torpes medidas de un gobernante engreído como Lersundi. ¿Y cuál es la máxima expresión escrita por Martí en aquellos momentos? Es un poema dramático: Abdala. Una concepción poética en que el ímpetu de libertad asume la fuerza creadora e irrumpe incontenible con la fuerza potente de la inspiración. Esa es, para nosotros, la primera prueba cierta y clara de esa vocación de escritor, asistida por la inspiración. El periodista se ha manifestado a la vez en los sueltos de 
la propia Prensa Libre y antes en El Diablo Cojuelo. Pero sus notas no alcanzan el tono y el vigor de aquella creación primera de su pluma.

Para quien hace de su vida un apostolado por las más grandes conquistas del hombre — su independencia y su dignidad-, el periodismo ha de ser necesariamente uno de sus modos de propagar sus ideas en esa necesaria conquista de prosélitos, como la oratoria será el otro vehículo indispensable para levantar la fe de sus compatriotas, enardecer los ánimos y combatir descreimientos. Oratoria y periodismo se adaptaron a maravillas en Martí para cumplir su apostolado. Pero sobre esas dos formas de la literatura, señoreó el escritor nato, dispuesto, por motivos ineluctables, a ser uno de los más completos escritores de su tiempo. La prueba de su originalidad esencial, que para Gabriela Mistral es Ia primera nota del escritor Martí, que halla en su tono y en su vitalidad, se toca con el agua fuerte de la oratoria, y de esa prueba sale triunfante, gracias a las virtudes verdaderas que pautaron todos los pasos de aquel "guía de hombres terriblemente puro".

El periodista es una derivación del escritor. Un cauce menor pero que lleva más directamente a donde quiere que vayan las ideas. Martí lo vio con claridad cuando dijo: "iTiene tanto el periodista de soldado!" La militancia es acaso la primera característica del periodista, y quizá no lo concibiera sino sirviendo a una causa. En Martí la palabra escrita tiene dos esenciales direcciones: una le lleva a aventar la idea de libertad para su tierra y de decoro para los hombres; otra va a la conquista de nuevos rumbos para la expresión literaria en América, llevando en si el mensaje de una renovación literaria, como ha apuntado Baldomero Sanín Cano. ¿No había dicho que "las guerras se hacen sobre caminos de papel?" El periodista estaba en su trinchera, con las columnas de letras saliéndole de la punta de su pluma, para juntar y fundar la hermandad de corazones, para levantar los ánimos. $\mathrm{Y}$ así, pudiera decirse que el periodista fue en él un oficio puesto al servicio de otro muy superior, el de hombre total, por la redención del hombre. Que Martí tenía todas las capacidades del gran periodista, y supo utilizar con tino los recursos todos del periodismo, es cosa sin discusión. Que supo los modos diversos de tratar los asuntos, según la índole de las publicaciones y los lectores a quienes se dirigía, que tuvo siempre el sentido de las medidas y la intuición de los efectos que deseaba lograr, es cosa que nos lo revela en sus mismos escritos, además de percibirse fácilmente en sus textos. Gran periodista, logró que su pluma fuera el vehículo más apto para propagar sus doctrinas. $Y \mid$ sus escritos quedan como el ideario de su misión apostólica, 
constituyendo el cuerpo de doctrinas en que quedó afirmada para siempre su concepción de una patria a cuya propaganda, formación, lineamientos y consolidación se entregó primordialmente.

\section{EIL ESCRITOR DIARIO NO PUEDE PRETENDER SER SUBLIME}

Esta frase, de una de sus libretas de apuntes, plantea la diferencia entre el periodista y el escritor, que Martí comprendió muy bien. Su iniciación periodística en Cuba había logrado en España un campo más adecuado y propicio, y aunque sus trabajos de esa índole no fueron muchos, ya se le vio el dominio en el manejo del artículo de carácter político, en sus colaboraciones en La Soberanía Nacional, de Cádiz, o en La Cuestión Cubana, de Sevilla, y su disposición para la polémica, en aquella oportunidad en que, con su compañero Carlos Sauvalle, sale a la defensa de la dignidad cubana, desconocida o maltratada, y aún en el folleto que publicó en 1873, La República Española ante la Revolución Cubana. que apareció antes como artículos en el mismo periódico de Sevilla.

Ya estaba iniciado este camino cuando, con sus carreras de derecho y filosofía y letras, llegaba a México, ansioso de prestarles ayuda a sus padres, que allí esperaba con ansiedad al hijo que iba a juntárseles, ávido de poner a contribución sus esfuerzos para rehacer la casa. Y el abogado y el graduado en letras no encontró modo mejor de iniciar su vida en la nueva patria americana que entrar en el campo del periodismo. No habían transcurrido muchos días desde su llegada y ya formaba parte de la redacción de la Revista Universal, donde Manuel Mercado, su nuevo amigo y protector, le encontró acomodo. En esas páginas inició sus colaboraciones como poeta, antes que como periodista. Pero después lo fue, y en el modo más singular acaso, pues tomó a su cargo una sección que no era la más adecuada para quien no hubiera nacido en el país. Los "Boletines" que con el pseudónimo de Orestes publicó, eran un comentario de la vida nacional en múltiples direcciones, desde la cultura hasta la política, y así se le vio ser un defensor de las ideas liberales que inspiraban 1: política de Lerdo de Tejada, a cuya defensa y propaganda se consagraba la Revista Universal. Martí escribió para esa sección, y siempre con altura y haciendo gala de su discreción y sentido del respeto a las ideas ajenas. Alli se mostró admirador de la fuetza original del país, y dio batallas en favor de su expresión propia en las artes, proclamando la necesidad de que México fuera más mexicano, desentendiéndose de las 
imitaciones europeas. Allí salieron a relucir sus primeros brotes de americanismo. Y cuando las circunstancias fueron imperativas, porque se maltrataba a la Revolución de Cuba, o se desconocían sus derechos, salió en defensa de su patria, con la mesura y la contención que su condición de extranjero le imponían.

En México ejerce por primera vez la profesión de periodista, que le da oportunidad de obtener una modestísima ayuda económica y de dar salida a sus ideas, a la vez que de darse a conocer y aun ganarse sitio entre los escritores del país. En alguna parte dirá: "Yo apenas había escrito para el público antes de ir a México, fuera de lo que requería el servicio de mi patria, y esto naturalmente había sido muy poco, porque la patria quiere más actos que palabras". Es precisamente en algunos de sus artículos de esa época de México donde ya vemos que el escritor tenía que sufrir la tragedia de la limitación periodistica. La propensión a la trascendencia es en él característica. En sus libretas de sus años de estudios en España ya apuntan las llamadas a lo abstracto y subjetivo, ya. habla de ideas propias, de concepciones originales, de libros de singular valoración para su edad, así su libro Yo. En México, en el oficio de "boletinista", la realidad cotidiana lo cerca, tiene que comentarla, pero se le ve contenerse una y otra vez para no salirse de su marco. Sin embargo, a veces lo sobrepasa, y algún pensamiento se sobrepone y queda. flotando sobre el comentario, como pensamiento solitario que remata el cuadro. Y cuando Martí se da cuenta de que se sale de sus límites de. "boletinista", pide perdón a sus lectores. Lo vemos en sus mismas palabras: "Y de la pequeñez se iba a lo alto este soñador espíritu de hombre. Como que no cabe en lo que le envuelve y se va de sí: así de una palabra renace una memoria; y de ellas esta necesidad de lo anchuroso, va adonde altas criaturas y espacios anchos lo convidan a lo absoluto y a loabstracto". Y el reproche contra esa propensión suya: "Enojoso esp'́ritu el de este pobre Orestes, que en vano quiere sujetar a una idea práctica lo que en él hay de sueño, de pensamiento doloroso y de afán vago". ¿No es esta una limitación que el periodismo imponía al escritor? Pero el escritor se sobrepuso siempre al periodista, de modo tal que aun en los: sueltos de revistas y periódicos en que escribió, se le pudo ver la paternidad, porque aquella propensión a grabar en frases perfectamente troqueladas le manaban de un elevado pensamiento.

Si Martí debía pedir excusa a sus lectores por aquella imaginación suya que se iba de lo pequeño a lo sublime, convengamos en que el es- 
critor tenía conciencia de que rebosaba los moldes periodísticos y por eso mismo pudo serlo en la excepcional forma en que lo fue.

SiENTE UNO, LUEGO DE ESCRIBIR, ORGULLO DE ESCULTOR Y DE PINTOR

En numerosas cartas y apuntes se refiere Martí a los libros que queria escribir, y muchos de ellos aparecen perfilados. Así le tentó un libro sobre "El concepto de la vida", acerca del cual dejó numerosas referencias, y pensó en una serie de pequeños libros dedicados a América, como aquel que escribió en homenaje a Guatemala. Esos libros no pudo escribirlos. Necesitaba escribir para los periódicos, porque ésta era una de las pocas maneras a su alcance para mantener su vida.

A su salida de México se ha situado en Guatemala. Pero allí su labor periodística fue muy escasa, y de ocasión, aunque tuvo el propósito de fundar una revista y aun dio a conocer su programa. En La Habana apenas hizo otra labor que la de orador, en las tribunas de los Liceos de Regla y Guanabacoa. Va a ser en Nueva York, en el año r88o y casi inmediatamente de su llegada, donde continuará esa militancia periodística, pero ya en circunstancias muy distintas. Ahora va a escribir principalmente sobre arte, $\mathrm{y}$ ha de hacerlo en un idioma que no domina aún: va a escribir en inglés para la revista The Hour. Es una revista que ha comenzado a publicarse ese mismo año de su llegada, una tevista que tiene cierto impetu juvenil, sin convencionalismo. $Y$ precisamente los juicios que Martí he emitido en sus conversaciones con el dibujante cubano Tomás Collazo, le abren este inesperado camino. El propio Martí se sorprende y deja constancia de su estado de ánimo en su libreta de apuntes: "De manera que sé de pintura. Ha comenzado a publicarse en Nueva York un periódico de artes y salones, The Hour, y sus redactores principales, Tiblain y Murphy, habían encargado a un cubano artista, maestro afamado del creyón, a Collazo, un crítico de arte. Collazo habló de mí en The Hour. Y héme, con dos papeletas para ver museos, camino de la colección de Mr. Stebbins y de Wolfes, y obligado a hacer de ellas una revista crítica en inglés. Yo pasé una tarde valiosísima en compañía espiritual con los más afamados maestros, por más que acusara en mis notas de superfluo a Fortuny, de escasez de invención a Meissonnier, de negligente y ligero a Detaille, de rosáceo y sedoso a Bouguereau. Yo sé un inglés bárbaro, y estas cosas me parecían justas, y me oprimían el corazón. Pero yo tengo confianza en mi energía y en estos ardientes efectos que 
involuntariamente inspiro". En The Hour aparecieron numerosos articulos sobre figuras contemporáneas de la pintura: Fortuny, Madrazo, Detaille, Courbet. También aparecieron unos artículos que su discípulo Quesada y Aróstegui identificó como de Martí, bajo el título de "Impressions of America". Y no fue ésta su única colaboración a la prensa norteamericana, en ese preciso año de su llegada a los Estados Unidos. En el periódico The Sun, que dirigía una gran figura apostólica, Charles Dana, halló Martí la más abierta acogida. Esta vez sus artículos no fueron escritos en inglés ni en español: los escribió en francés y se traducían para el afamado periódico neoyorquino. Dos de esos artículos, uno sobre "Poetas españoles contemporáneos" y el otro dedicado al poeta ruso Aiejandro Puckine, fueron traducidos y dados a conocer en periódicos de Hispanoamérica.

Vemos, pues, que la labor periodística de Martí se ensancha, abarcando temas universales. Ya no es el comentario de la vida cultural y política que le rodea, como en México. Ahora es la crítica de grandes pintores y de poetas de muy diversas nacionalidades. Pronto suspendió, sin embargo, esta colaboración en la prensa norteamericana. A su llegada a la gran ciudad del Norte, Martí se había incorporado a los empeños revolucionarios de Calixto García, en los que se inició en Cuba conjuntamente con Juan Gualberto Gómez y ocasionó su segunda deportación a España. Y al fracasar la llamada Guerra Chiquita y quedar paralizada su actividad política, vio de momento que necesitaba buscar más adecuados horizontes para sus empeños, y marchó a Venezuela. Su estancia en la patria de Bolivar sería también muy breve, dos números de la Revista Venezolana, que concibió y realizó de puro idealista en los meses escasos en que vivió a la sombra del Avila azulado. Esa revista nos ofrece el material más útil para darnos cuenta de la calidad del escritor que había en Martí, por una parte, y por la otra, de su concepto sobre el estilo y sobre el carácter de las publicaciones. Porque si no escribió los libros que meditaba, y muchos otros que pudo haber escrito, no sólo dejó fragmentos que pueden considerarse destinados a ellos, como los varios que hallamos con indicación precisa que los remite a "El concepto de Ia vida", sino también abundantísimas anotaciones que con el concepto de escritor se relacionan, permitiendo fijar su alta preocupación por esa vocasión suya, que es tan poderosa casi como la de su apostolado. La poesía fue primordialmente la forma en que se volcó su espíritu; y también incesante motivo de meditación, no sólo en sus trabajos publicados sobre poetas - en primer lugat su gran ensayo sobre Walt Whitman- sino en 
tantos apuntes de sus libretas de notas, que nos dan numerosos enfoques. scbre su concepción creadora. El escritor, el poeta, el crítico, el periodista, son formas varias de un mismo espíritu que creaba y conocía al mismo tiempo los modos diversos en que era preciso usar el poder de la mente, según fuera la dirección y el contenido del mensaje.

Se ha señalado ya que la obra de Martí guarda una absoluta unidad presidida por el amor. Es asombroso comprobar esa unidad en todo lo que pensó y escribió, al punto que ya no podemos esperar que algo venga a torcer esa idea, puesta a prueba según han ido apareciendo nuevos escritos y apuntes inéditos.

Pero si existe tal unidad, existen también grados en la intensidad de su dedicación. En los artículos de la Revista Universal, de México, es donde primeramente hallamos los brotes de la fuerza y originalidad de Martí. Aún queriendo contenerse, como ya vimos, su tendencia a lo grandioso y sublime, obra de la fuerza de la originalidad que llevaba encerrada en su pecho, dejaron destellos de su personalidad y de sus rasgos: como escritor. En esos momentos iniciales sus pensamientos estaban ungidos por un hermoso sentido americanista que comenzaba a brotarle con pujanza. A la literatura y al arte de México y a la poesía americana en general, se refirió con frecuencia, para pedir, en nombre de su propio nacimiento original, un arte y una literatura nuevos. "Las manos que han surgido de una tierra virgen, no han debido ser hechas para aplaudir las postrimerías de una tierra cansada y moribunda". Era así como en sus. boletines predicó la absoluta autonomía de nuestras tierras, de todo lo europeo. Así dirá: "¿Por qué en la tierra nueva americana se ha de vivir la vieja vida europea?" En esos modestos artículos en que comentaba la diaria actualidad, ya lo vemos, apunta el hombre que sobrepasa el estrecho contorno que le marca su misión informativa.

En la Revista Venezolana hará gala de ese dominio suyo del estilo, y lo defenderá de juicios que traten de menoscabarlo. En esas páginas, el escritor se alzó a gran altura, en el ensayo dedicado a Cecilio Acosta, que hemos de considerar el primero en su carrera de escritor y que condensa los mayores hallazgos literarios, al punto de que es en esa revista donde parece sentirse en plenitud al escritor. $Y$ alli hallamos esta frase: "siente uno, luego de escribir, orgullo de escultor y de pintor". Sólo dos números publicó, como sabemos, de esa tevista. En cada uno de ellos hay un trabajo fundamental de Martí: el consagrado a Miguel Peña, en el primero, el que escribió al recoger los últimos suspiros de Cecilio Acosta, en el segundo. Esas breves páginas son, para la historia del escritor, fundamentales, por- 
que además de haber puesto a contribución en esos ensayos insuperables lo mejor de sí, al punto de que se ha dicho reiteradamente que en su Cecilio Acosta vació Martí cuanto llevaba dentro, dejó además unas notas sobre el carácter de la Revista Venezolana, que dan luz sobre su concepción del arte de escribir, y nos es, además, útil para esos distingos que hacemos entre escritor y periodista, que no es por razón de la materia en sí, lo repetimos, sino por causa de la "intensidad". Los párrafos de mayor significación, en esas notas, son los que se refieren al estilo, y ya podemos ver cómo para Martí el color juega papel de importancia en el escritor, porque "el escritor ha de pintar, como el pintor". Se le reprocha de amanerado y pulcro el estilo de algunos de sus trabajos. Martí aclaró su concepto, y dijo: "Uno es el lenguaje del gabinete; otro el del agitado parlamento. Una lengua habla la áspera polémica: otra la reposada biografia". Tal distinción en el estilo sería aplicable a la diferencia entre lo que es trabajo literario y lo que es periodístico, sin olvidar que en función de corresponsal Martí se alzó a tal altura, que no deja espacio para distinguir y separar lo uno de lo otro.

\section{¿QUÚ MAYOR TORMENTO QUIERE USTED QUE SENTIRSE CAPAZ} DE LO GRANDIOSO Y VIVIR OBLIGADO A LO PUERIL?

La precipitación con que tuvo que salir de Caracas, cuando comenzaba a circular el segundo número de la Revista Venezolana, le obliga a despedirse de sus amigos por medio de una carta dirigida a Fausto Teodoro de Aldrey, director de La Opinión Nacional. Llevaba una dolorosa certidumbre: "En los países elementales, en la esfera intelectual, es muy difícil la vida de los hombres virtuosos". Sus experiencias penosísimas de Guatemala se habían repetido. Antes como ahora las ideas eran perseguidas por la tiranía. Pero su carta de despedida era una reafirmación de su supremo amor a América, que esta vez concretó en frase brillante e imperecedera, llamada a eterno brillo: "De América soy hijo: a ella me debo". Quien había llegado a Caracas, y sin preguntar dónde se comía ni bebía, fue a dialogar con la estatua de Bolívar, salía como desterrado de la patria que su espada había libertado, pero entonando un canto y una promesa de servicio, como de hijo agradecido.

Tras su llegada a Nueva York, recibe carta de los directores de $L a$ Opinión Nacional, concretándole proyectos de que ya habían hablado, no sólo para que les representara en la obtención de avisos de casas norte- 
americanas, sino para of recerle que fuera su corresponsal en el gran país. Y su respuesta fue enviar, por el mismo barco que lo habia traído, sus primeras correspondencias. Las inicia con un episodio que ha conmovido a la Nación: el atentado al Presidente Garfield. Cuatro horas después de haber llegado el correo, en diez galeras del periódico de Caracas aparecía el extenso trabajo, firmado con las iniciales M. de Z., pues habían acordado mantener la mayor reserva en cuanto al autor de esa colaboración. No seguiremos todo el proceso suscitado por esas correspondencias, en las que Martí puso un vivísimo entusiasmo, llegando a decir que le fueron cosas del alma. Los directores sólo buscaban aprovechar, para conveniencia propia, la pluma infatigable y magnífica, pero siempre que no lastimara los intereses del periódico, o reflejara ideas contrarias al mismo. $Y$ se dio el caso que correspondencias enteras no fueron publicadas y otras sufrieron mutilaciones. Llegó a tal punto la inconsecuencia, que a los pocos meses de haberse iniciado esta colaboración, pedían a Martí que escribiera en lo sucesivo algo con sabor ultramontano, para congraciarse con el "fanatismo que reina hasta en los hombres más encopetados". Frenéticamente se consagra Martí a esa labor de corresponsal. No sólo escribe sobre los Estados Unidos, comentando los sucesos más importantes, sino que envía correspondencias en que se reflejan sucesos de la vida en España, Francia, Rusia, Italia, Alemania. $Y$ en esas crónicas parece como si hubiera tenido una visión directa de cuanto ha sucedido, en la vida social, política y cultural de cada país. No hace meros relatos de acontecimientos: sitúa las escenas, revive los personajes, baraja con maestría la historia y las anécdotas. $Y$ esas correspondencias, que van conociéndose en otros países de América y que merecen con frecuencia su reproducción, no satisfacen a los señores Aldrey, que lo acosan con indicaciones de cómo ha de escribir sus trabajos. No les interesa tanto el comentario de Martí, como el cúmulo de noticias sueltas, para gusto de toda clase de lectores. "Abundantes notas sueltas" es la demanda continua. Martí, deseoso de prestar su apoyo al periódico, que es, además, su única fuente de ingresos en esos momentos, accede y escribe pequeños comentarios sobre las más variadas materias. El periódico los junta y publica en una "Sección Constante", donde se encuentran los más diversos temas.

Llegó a serle intolerable la actitud de los directores del periódico. Se quejaban de la extensión de artículos como los consagrados a Darwin y a Emerson, y también de su estilo, especialmente de que sus párrafos eran muy largos, y debían ser cortos. Por último le hacían esta indicación: "procure en sus juicios críticos no tocar con acerbos conceptos los vicios 
y costumbres del pueblo norteamericano". Su espíritu no pudo soportar tanta desconsideración. $Y$ dejando sin respuestas las últimas cartas, suspendió sus colaboraciones.

Había sido un aprendizaje útil el escribir esas correspondencias, y se sentía compensado sabiendo que se habian seguido con mirada vigilante y grandísimo interés. Buena prueba sería que no habían pasado seis meses cuando ya La Nación de Buenos Aires engalanaba sus páginas con trabajos de la misma índole, salidos de la misma pluma de Martí. Curioso dato es que el primer trabajo con que en La Opinión Nacional inició sus correspondencias, fue consagrado a la muerte del Presidente Garfield, y el primero que aparece en La Nación recoge el episodio de la muerte de Guitteau, el asesino de Garfield. Una carta de Bartolomé Mitre y Vedia, de la gerencia de La Nación, le había hecho saber la necesidad que tenían de un corresponsal en los Estados Unidos, sin haber hallado la persona que pudiera serlo adecuadamente, hasta habérseles presentado esta oportunidad. Aunque tratado con las mayores consideraciones, Martí tuvo también que sufrir las podas en algunos de sus trabajos, y así se lo comunica el propio Mitre, tras expresarle la buena acogida que su primera correspondencia logró, mereciendo "los honores de la reproducción en numerosos periódicos, algunos de los cuales le han dedicado - y a su autor por consiguiente- muy favorables conceptos".

Su primera correspondencia ya sufrió supresiones, por su "extremado radicalismo en la forma y en las conclusiones", al tratar de la organización política y social y de la marcha de los Estados Unidos, que habia hecho suponer que se abría una campaña contra ese país, como cuerpo político, como entidad social, como centro económico, silenciándose por otra parte, a juicio de la dirección del periódico, las grandes lecciones que ofrecía a la humanidad. Querían, y eso reconocen que ya había hecho Martí en trabajos anteriores, que hiciera completa justicia a lo que hay de grande, de noble y de hermoso en los Estados Unidos. Martí comprendió la razón que asistía al periódico y sin duda meditó sus razonamientos, y al contestarle, aludió a su carta, considerándola "sólo en lo cuerda igual a lo generosa". Así ha llegado a la cumbre del periodismo. Ya no tendrá aquellas limitaciones de sus primeros tiempos de "boletinista", cuando se creía obligado a pedir perdón a sus lectores cada vez que su entusiasmo le llevaba a pensamientos abstractos y grandiosos. Ya no tendrá que lanzar aquella queja de la misma época de La Opinión Nacional, que lo cercaba por todas partes: " $¿$ iué mayor tormento quiere usted que sentirse capaz de lo grandioso y vivir obligado a lo pueril?" Ahora su nombre 
se cimenta en América, y va creciendo su fama, que era cosa que no le interesaba mucho para sí, pero necesaria para su futura obra revolucionaria. Como dijera de su maestro Mendive, pensaría que era bueno ganar fama literaria para que su nombre pudiera inspirar mayor fe patriótica.

Esas correspondencias fueron la base de la fama de Martí en nuestra América. Al pie de ellas su nombre circuló por todas las tierras del Sur, levantando admiraciones en los más valiosos escritores, contándose en primerísimo lugar, el gran Sarmiento y Rubén Dario, el poeta que se iniciaba teniendo como maestro al gran prosista José Martí, como después; escribiera en sus Memorias.

La Nación le había hecho observaciones acerca de la naturaleza de las cartas que le pedía, y Martí comprende y recibe con agrado las sugestiones. "Queda, pues, dicho que leí con verdadero gozo sus observaciones. acerca de la naturaleza de las cartas en que su buena voluntad permite que me empeñe, y que el gozo fue tanto porque vi mis pensamientos en los suyos, cuanto porque penetró usted en los mios". Aprobó Martí las. sugestiones introducidas, comprendiendo que por ser aquella su primera: correspondencia, hubiera parecido, como la empresa creía, con aire de prevenida y acometedora. $Y^{\prime \prime}$ agregaba después una reflexión que corrobora lo que desde el comienzo venimos apuntando: que Martí sobrepasaba los moldes del periodismo y se veía constreñido a dominar sus ímpetus, para no rebasar los límites: "Es mal mío no poder concebir nada en retazos, y querer cargar de esencia los pequeños moldes, y hacer los artículos de diario como si fueran libros, por lo cual no escribo con sosiego, ni con mi verdadero modo de escribir, sino cuando siento que escribo para gentes que han de amarme, y cuando puedo, en pequeñas obras sucesivas, ir contorneando insensiblemente en lo exterior la obra previa hecha ya en mí". En esa misma carta, preciosa para penetrar los conceptos de escritor y periodista en cuanto a Martí, hay numerosas frases que valen para precisar otras ideas suyas, tal la de la crítica. Se le dejaba en libertad para. censurar lo que, al escribir sobre las cosas del Norte, hallara digno de censura. "Y esta es para mí, comenta Martí, la faena más penosa. Para. mí la crítica no ha sido nunca más que el mero ejercicio del criterio". Y entrando en precisiones de su entusiasmo por la alabanza y su poco gusto por la censura - "en las censuras, de puro sobrio, peco de malo"- llega a la precisión de su fórmula puesta en práctica en aquellas correspondencias que durante un año escribió para el diario de Caracas. Veamos cuál era ese método en sus propias palabras: "El método para las cartas de Nueva York que durante un año he venido escribiendo, hasta tres meses. 
hace que cesé en ellas, ha sido poner los ojos limpios de prejuicios en todos los campos, y el oído a los diversos vientos y luego de bien henchido el juicio de pareceres distintos e impresiones, dejarlos hervir y dar de sí la esencia, cuidando no adelantar juicio enemigo sin que haya sido antes pronunciado por boca de la tierra, porque no parezca mi boca temeraria; y de no adelantar suposición que los diarios, debates del Congreso y conversaciones corrientes no hayan de antemano adelantado. De mí, no pongo mảs que mi amor a la expansión - y mi horror al encarcelamiento del espíritu humano. Sobre este eje, todo aquello gira. ¿No le place esta manera de zurcir mis cartas? Ya las verá sinceras,-- con lo que usted, que lo es tanto, no me las tendrá a mal".

\section{LOS QUE VIVEN DEL CIELO COMEN MUY POCO DE LA TIERRA}

El capítulo de las angustias económicas de Martí no se ha escrito aún con la amplitud que merece. A todo lo largo de su epistolario vemos ese acoso de las estrecheces, sin podernos explicar cómo pudo tener fuerzas para seguir adelante, con la carga abrumadora que casi siempre llevó a cuestas. En México el sueldo que le pagaba la Revista Universal por su labor de redactor fijo era insuficiente para su modesta vida, y apenas pudo ayudar a sus padres y hermanas que, allá como aquí, tuvieron que seguir trabajando duramente para soportar la carga de la casa. Cuando la caída de Lerdo le obligó a buscar refugio en Guatemala, fue lleno de ilusiones, creyendo que con su esfuerzo se abriría camino. Pero si leemos las cartas que escribió a Mercado en esa época, sobre todo al regresar casado, notaremos que nunca fueron mayores sus angustias, y que en ninguna parte sufrió tanto la rudeza de la mala fortuna. Todo cuanto había hecho por servir, con sus clases numerosas y muchas gratuitas, con sus artículos y aun con su libro Guatemala, se estrellaba contra cierta animosidad hipócrita. Se sintió desconocido y desdeñado. Nunca exprimió -antes ni después-- el zumo del dolor y la ingratitud tan abundantemente como en esa tierra a la que llegó lleno de esperanzas. Allí aprendió más de una lección, y especialmente, como escribe a Mercado, le enseñaron una gran verdad: "Con un poco de luz en la frente no se puede vivir donde mandan tiranos". Se vio acorralado y tuvo que salir, acogiéndose al fin, desesperadamente, a la oportunidad que se abría en Cuba con la Paz del Zanjón, dando oídos a los llamados de Doña Leonor y a las súplicas de su esposa. Angustiado preguntaba a Mercado: "-¿Qué se ha de 
ser en la tierra; si ser bueno, ser inteligente, ser prudente, ser infatigable y ser sincero no basta?"

En los Estados Unidos, donde encuentra sitio adecuado para continuar viviendo, halla un centro natural para sus actividades. Pero no desaparecen sus dificultades económicas. $Y$ cuando regresa al país, después de la experiencia no menos dolorosa de Venezuela, tiene en ocasiones que trabajar en tiendas de comercio, como empleado de oficina, porque sus colaboraciones en revistas y periódicos apenas le producen lo adecuado para vivir. Las correspondencias a Venezuela no le rendían más de cien pesos mensuales, y las que envió después a La Nación no alcanzaban esa cifra. Sin embargo, se sentía con fuerzas para redoblar sus esfuerzos, con tal de aumentar sus entradas, siempre que no tuviera que rebajar su inteligencia a ser mero amanuense de oficina. Si conservaba en un cuadro - como estupenda maravilla - el primer peso que ganó en Nueva York como crítico de arte, era porque le recordaría siempre que allí supieron apreciar desde el primer momento sus valores en el terreno intelectual. No le asustaba el trabajo; lejos de eso, nadie halló mayores satisfacciones en él, al punto de que parece que es una necesidad para su espíritu aturdirse trabajando, mientras llegaba el momento ansiado de entregarse a la obra de la independencia. Cuando se ve llevado a dedicar sus empeños en otras direcciones, lucha por salirse del cerco que lo oprime. En este forcejeo pasó mucho tiempo, si no diríamos que casi toda su vida. A Mercado le hace innúmeras confesiones. "Estoy como roído-del ansia de vivir en acuerdo conmigo mismo; y en desobediencia a los mandatos que llevo en el alma".

Como escritor ve ante sí dos posibilidades: el libro y el periódico. En ellas está su salvación. De sus "correspondencias" piensa - y le consulta a Mercado-, si ha hallado al fin el molde natural, aunque pocas veces se siente satisfecho con lo que hace, teniendo que escribir al pie de otros quehaceres, con precipitación obligada. Las dos posibilidades - libros y artículos para periódicos - le dan sin cesar vueltas en la mente. "Es que quiero ver cómo me devuelvo a mí mismo, y me pongo en condiciones de trabajar en labores más útiles y decorosas que éstas en que ahora ando. Pues, puesto que he traído cariño en el pecho, es para vaciarlo. Y si no lo hago, falto a mi deber hacia los demás, que es mayor que mi deber hacia mí". Las cartas se sucedían, pero Martí no se decidía a plantearle a su amigo la ayuda que necesitaba. Al fin, a fines de septiembre de 1884 , cuando se ha separado del intento de organización revolucionaria promovido por Gómez y Maceo, y ha escrito su conocida carta 
al general Gómez, le escribe extensamente a Mercado. Toda esperanza de trabajar por su patria ha quedado en suspenso. Necesitará ahora la ayuda que tantas veces le ha indicado, sin precisarla. Aspira, recogiendo labores de aquí y de allá, a evitar el caer nuevamente en la mesa de comercio. Aspira a escribir para varios periódicos a la vez, de modo que pueda trabajar en sus propias vías, "que es el único modo de dar fruto". Y concretando por primera vez sus aspiraciones, le dice: "Dos cosas se me ocurren, y una la tenía pensada mucho tiempo ha: ¿vendría bien para el Diario Oficial de México, con una remuneración que, sin ser excesiva, compensase en algo la labor, de 50 a roo, según el tiempo empleado, una especie de redacción constante de asuntos norteamericanos, estudiados, sin comentarios comprometedores, en cuanto, y ahora es mucho e importantísimo, hiciese relación a todos los pueblos de nuestra raza, y en especial al mexicano?"' Una o dos cartas cada semana, que tuvieran al tanto a los lectores de México de todo asunto que se refiriese a las relaciones de los Estados Unidos con nuestros países hispanoamericanos.

El otro plan, seguramente de su mayor agrado, lo presenta así: "He imaginado sentarme en mi mesa a escribir, durante todo el mes, como si fuese a publicar aquí una revista. Sale un correo de Nueva York para un país de los nuestros: escribo todo lo que en éste haya ocurrido de notable: casos políticos, estudios sociales, noticias de letras y teatros, originalidades $\mathrm{y}$ aspectos peculiares de esta tierra. Muere un hombre notable: estudio su vida. Aparece, acá o en cualquier otra parte del mundo, un libro de historia, de novela, de teatro, de poesía: estudio el libro. Se hace un descubrimiento valioso: lo explico, luego de entenderlo. En fin, una revista hecha desde Nueva York sobre todas las cosas que puedan interesar a nuestros lectores cultos, impacientes e imaginativos; pero hecha de modo que pueda publicarse en periódicos diarios". Esto, en cuanto al panorama de ideas que habrían de formar el cuerpo de su trabajo. En cuanto al plan en sí, consistía en una especie de cadena de periódicos, dando oportunidad a los que entraran en su plan para publicar un número de artículos - "siete, ocho, diez, yo no sé cuántos, porque Ud. sabe-le aclara a Mercado-que ni el corazón ni la mano se me enfrían". Y hablaba ya de algunas posibilidades, citando El Siglo, del Uruguay y El Mercurio, de Chile. De sus artículos, en esa forma distribuidos, "unos serían de crítica, otros de bibliografía, otros de biografías, otros, los que interesarían más acaso, correspondencias sobre varias materias". Y aclaraba la índole de su trabajo: "Naturalmente, ese trabajo, que es más que el de un redactor diario asiduo, no lo podría hacer para un periódico solo, a 
menos que compensase por sí solo el tiempo empleado en él". Y agregaba esta elocuente nota, bien reveladora de la modestia de sus aspiraciones: "Con \$120.00 me basta para la vida: tengo probabilidades de que los periódicos que le he dicho de Montevideo y Santiago tomen esta serie de trabajos, que se publicarían en el periódico de cada país a un mismo tiempo: y eso me habilita a of recer toda esa labor por $\$ 40.00$ oro americano al periódico mexicano que viese utilidad en ella. Ud. me cuidaría, por serme vital, de la constancia de la paga. ¿No ve que me debe estar dando vergüenza hablarle de esto?"

Pasarán meses, años, antes de que logre ver convertido en realidad ese anhelo de hallar acogida en un diario de México. Hará, una y otra vez, alusión a sus quehaceres de comercio, que tanto lo deprimen. Traducirá para aumentar un poco sus entradas y poder darse el gusto de llevar a Don Mariano a pasar unos meses con él, y después a Doña Leonor. Aquellas ideas de consagrarse por entero a escribir libros o art'culos para los diarios, le vuelven con insistencia, sabiendo que contribuiría a la salud de su cuerpo y de su mente.

De pronto ve iluminarse su vida con un nuevo proyecto que parece cristalizar. Es en marzo de I886 cuando le escribe a Mercado: "Tengo ocupado el espíritu, como un niño que jugase con un rayo de sol, con ciertos pensamientos de resurrección, de que Pablo Macedo tiene la culpa. A él ha ocurrido espontáneamente la idea de ponerme en camino de empezar una serie de publicaciones útiles americanas, cosa en que pienso desde hace muchos años con la insistencia de quien adora lo que le es natural, - y objeto único grato de mi vida- perdida como tengo la esperanza de ser por ahora, y por siempre acaso, útil a mi patria. Estoy regocijadísimo con esta idea, no sólo porque con la alegría que me trae, y la nobleza de la ocupación, me salvaría lo poco que me queda de salud y de espíritu, sino porque como, sin que yo lo haya buscado, se me viene a la mano lo que por tantos años preparo y tanto deseo, deduzco que es natural y posible que suceda, y ya lo doy por hecho, y a mí por sacado de la inactividad y la tristeza que me comen". Mucho habia meditado los detalles de esa empresa, más grata que cualquiera otra, porque era la que mejor se avenía con su real vocación de escritor. "Tengo muy meditado lo que ha de hacerse en este género de empresas, y con poco que me ayuden la fortuna y los amigos de la educación en México, dentro de poco tendré establecida una noble y extensa empresa americana, en la que vaciaré todo lo que tengo de previsor en el juicio y de amante en el alma: y ayudaré a hacer los hombres conforme a los tiempos". Esa idea de hacerse editor de 
libros baratos y útiles, de educación y materias que la ayuden, inspirados en la naturaleza y necesidades de nuestros pueblos, estuvo alimentando su fantasía por mucho tiempo, y movió sus continuas apelaciones al amigo de México. Parecía ser un momento decisivo para su vida. Tenía confianza en sus fuerzas, pero presentía que se agotaban en trabajos inútiles. "Saco de mí, sin cansarme, una energía salvaje; pero noto que estoy llegando ya al fondo de mis entrañas".

Uno u otro proyecto apuntaban en sus cartas alternativamente, como soluciones urgentísimas. $Y$ tan poco dado a mostrarse en su intimidad dolorosa, llega a escribirle a Mercado: "Mi Consulado (el del Uruguay) que me venía ayudando, se me acaba el mes próximo. Si no me saca Ud. por sobre su cabeza en esto de los diarios, tendré de nuevo. - sin que nadie, eso sí, note mi desfallecimiento-- que acudir a una colocación vulgar de comercio, de muchas horas y retribución mezquina, a donde vuelva mi vida a lo que ha sido en estos tiempos últimos, avera de pesebre, a que se la coman los caballos". En esa carta desesperada -22 de abril de r886-, su gran angustia acumulada se desbordó a tili punto, que antes de transcurrir un mes vuelve a escribirle a su amigo, ahora para darle un abrazo de gracias. Mercado había logrado concertar un plan de colaboraciones para El Partido Liberal, periódico en que andaba el Coronel Villada, director de la Revista Universal, en la cual hizo sus armas periodísticas años antes, al llegar a México. $Y$ no una, sino dos correspondencias escribe y salen juntas, tal es la avidez con que acoge su nueva labor. No ha escrito media docena de cartas al periódico, y se presenta una grave situación entre México y los Estados Unidos por cuestiones de frontera. Martí escribe, después de mucho meditarla, una correspondencia llena de previsiones, con el ánimo puesto en àyudar a evitar la guerra, contribuyendo a una fácil salida. La solución que el asunto tuvo la consideró una victoria que se había ganado para México y el cuidado que puso en sus comentarios acerca de las relaciones entre los dos países, fue grande, como estas palabras indican: "Peso cada palabra, y le doy vueltas, y no la dejo por acuñada hasta que creo que no lleva nada de perniciosa o indiscreta". El plan de sus futuras correspondencias para México envuelve un amor muy grande al país, acerca del cual había dicho a su amigo, en el momento de peligro: "jSufro tanto de esto como si viera en peligro de muerte a mi propia tierra!"

En el mismo año r886 comenzó a colaborar en un periódico de Honduras, La República, al que envió muy importantes trabajos, entre ellos. uno titulado "La educación en los Estados Unidos", que no aparece re- 
cogido en sus obras, y que publicamos recientemente en una obra nuestra. También logró que sus colaboraciones fueran aceptadas en un periódico de Montevideo, La Opinión Pública, donde aparecieron muchos de sus trabajos valiosísimos. Así había logrado, aunque con esfuerzo y tiempo, lo que tanto anhelaba: escribir a la vez para varios periódicos de América, llevando a todos ellos su potente aliento americano. Una mayor holgura económica le dará ánimos y mayor energía, ganando amplitud y firmeza en su empeño de agrandar horizontes en su prédica. $\mathrm{Va}$ a sentirse un poco más libre, sin la amenaza del águila enjaulada, a que tantas veces hace alusión. "Me han contado de un águila presa que vivió sometida a alimentarse de la pitanza de un jilguero". Ahora se revolverá entre sus papeles, con la fiebre de la creación, trabajando en lo que es su campo natural. Escribiendo para La Nación de Buenos Aires, para El Partido Liberal de México, para La Opinión Pública de Montevideo, para La República de Honduras, para El Economista Americano, que ha vuelto a salir en Nueva York. Hace un examen de sus entradas, en carta a Mercado: "Tengo, pues, de entrada viva \$50.00, que me manda Ud.; \$40.00 que por dos cartas mensuales me paga La Nación; unos $\$ 30.00$ que, un mes con otro, da el Consulado-y \$25.00 más ahora que, por tres meses al menos, vuelve a publicarse El Economista, a cuyo dueño sirvo, tanto para ayudarlo, porque es bueno-como por unir esa pequeñez, que no puedo desdeñar. De $\$$ I20.00, pues, a $\$ 150.00$, será ahora mi entrada". Esa entrada no podía considerarla fija, expuesta a mermas por alguna razón, uno y otro mes. Lo que le llevaba a hacerse esta reflexión: "Y ipasan de veinte los diarios que publican mis cartas, con encomios que me tienen agradecido, pero todos se sirven gratuitamente de ellas, y como Molière, las toman donde las hallan!" Esta pequeña bienandanza se traduce en un crecimiento de sus empeños. $Y$ vuelve la idea de los libros: "con los libros, que son mi deseo, sin caer de nuevo en otro empleo de comercio".

\section{FORTALECER Y AGRANDAR VÍAS ES LA FAENA DEL QUE ESCRIBE}

El primer libro con que Martí pone en práctica su proyecto de dar obras de interés para nuestra América, fue Ramona, que tradujo del inglés y editó por su cuenta, a un costo de más de mil pesos. "Lo escogí -le dice a Mercado- porque es un libro de México, escrito por una 
americana de nobilísimo corazón, para pintar, con gracia de idilio y color nuestro, lo que padeció el indio de California, y California misma, al entrar en poder de los americanos. Es novela, no historia, novela discretísima, y sin aspavientos de elegía, ni más pasiones que las nobles". Sus actuales ingresos apenas le permitían afrontar el costo de la edición; quedaría a deber la mitad, por lo menos, pero contaba con el mercado de México para una gran venta. La realidad, sin embargo, no correspondió a sus esperanzas, pues había considerado la publicación de ese libro base de su independencia económica. $Y$ hay que reconocer que multiplicó su propaganda, enviando a los periódicos de América copias de su prólogo y numerosas notas y avisos, que debían llamar la atención sobre el libro.

Las correspondencias, por suerte, han de seguir ocupándole su atención y continúan siendo el molde más personal en que daba forma a sus grandes inquictudes, a su insaciable afán creador. Si cstá en un medio tan adecuado, que puede permitirle moverse en escenario digno de él y de su mente, ha de sobresalir, como ocurrió, recogiendo en las sonoridades de su prosa centellante los estremecimientos colosales de la vida que le rodea, pudiendo considerársele sin rival en esa forma de unir en una sola pieza, acabada en sí y de ajustadas dimensiones, los sucesos e ideas predominantes en su hora, con los propios pensamientos, sin sacrificar éstos ni desvanecer aquéllos. Que Martí daba de sí en el comentario, al punto de que sus ideas llegaron a predominar, lo que debía serle un gran alivio y un íntimo goce, lo podemos notar en un comentario de Sarmiento, que merece recordarse: "Quisiera que Martí nos diera menos Martí, menos latino, menos español de raza y menos americano del Sur, por un poco más del yankee, el nuevo tipo de hombre moderno, hijo de aquella libertad cuya colosal estatua nos ha hecho admirar al lado de aquel puente colgado de Brooklyn..." Gracias a que dio de sí, en sus correspondencias quedó lo más personal y valioso de su pensamiento, quedó su obra maciza, única, trascendente e imperecedera, porque valiéndose de sus recursos y modos propios, insufló su aliento supremo en el recuento de lo transitorio. Escribió sus correspondencias sin tener que traicionar o disimular su pensamiento, sin tener que escribir "contra el alma, o sin ella".

$\mathrm{Y}$ ya en este momento de cierta tranquilidad espiritual, surge una nueva empresa en que pondrá, como siempre, toda su fe indestructible en el bien; surge La edad de oro. Parece que el anuncio de esa tentativa de revista infantil hizo esperar que le mermara altura a su perso- 
nalidad, ya bien destacada, pero sucedió al revés: pronto se dieron cuenta, los que tal esperaban, de "que se puede publicar un periódico de niños sin caer de la majestad a que ha de procurar alzarse todo hombre". Y bien sabemos que en su obra ocupa lugar solitario y preferente esa obra en que, reunidas las cuatro entregas que publicó, se revela lo que fue su afán primordial: preparar a los niños para hombres de su tiempo, y muy principalmente, para hombres de América. $\mathrm{Y}$ su triunfo fue superior, porque esa obra le dio nueva oportunidad de mostrar sus asombrosas dotes de escritor, capaz de llevar a un estilo sencillo y directo la misma fuerza y colorido de sus trabajos mayores. La edad de oro no nos parece que pueda considerarse labor periodística, aunque se publicara en forma de revista. Cada uno de sus trabajos resultan creaciones singulares, en géneros diversos. $\mathrm{Y}$ de paso veamos una vez más cómo obra tan pura y elevada murió a manos de la intransigencia, que quiso imponer direcciones al pensamiento de Martí. La edad de oro fue concepción suya, concepción de su amor a los hombres y a los niños, y nadie será capaz de pensar que necesitaba cambios en la ruta emprendida. Sin embargo, su editor quería que Martí hablase del "temor de Dios", y que el nombre, de Dios, y no la tolerancia y el espíritu divino, estuvieran en todos los artículos e historia. Y la pregunta que hace al amigo a quien le escribe sobre ese suceso, es bien explicativa de sus ideas en ese terreno: "¿Qué se ha de fundar así, en tierras tan trabajadas por la intransigencia religiosa como las nuestras?"

Y ya estamos en el último peldaño de la misión del periodista, el que da acceso a su periódico Patria, creado para favorecer la obra del Partido Revolucionario Cubano, en el que concentró la dirección definitiva de todos los esfuerzos para alcanzar la independencia. El primer número apareció el I4 de marzo de 1892, y en su artículo "Nuestras Ideas" expuso los propósitos que presidían su aparición, que no eran otros que contribuir a la organización que habría de preparar a los hombres para luchar por su libertad, juntándolos en un propósito común. "Nace este periódico - son las palabras finales-a la hora del peligro, para velar por la libertad, para contribuir a que sus fuerzas sean invencibles por la unión, y para evitar que el enemigo nos vuelva a vencer por nuestro desorden".

Patria es el auténtico periódico al servicio de la revolución que preparó y organizó, para desembocar en la "Guerra de Marti", con lo cual vemos que desde el principio, tras la creación del Partido Revolucionario Cubano hasta el último momento del triunfo, el esfuerzo de la in- 
dependencia no tuvo más norma que la que el Delegado instituyó, predicándola en la tribuna y en el periódico. Patria es el instrumento de su propaganda, el exponente de su fe en Cuba, la semilla de los nuevos. frutos que quiere que nazcan en la República el lazo de unión de los cubanos, la oportunidad para el elogio de toda obra generosa y de toda alma sincera y pura. En Patria florecen las virtudes que anhela para sus: hermanos, los bienes que desea para su tierra, los caracteres que deben iluminar su provenir.

Nunca el periodista lo fue tan plenamente como desde las páginas: de Patrit. Es que estaba en servicio de su misión primera: la misión apostólica que entraba en su etapa final. $Y$ aquella idea suya de la semejanza entre el periodista y el soldado, se robustece ahora, cuando dice: "Trincheras de ideas valen más que trincheras de piedra". Y cuando se dirige en la persona de Angel Peláez a los ejemplares amigos de Cayo. Hueso, ya presa de la fe en desarrollo final y definitivo de los impulsos patrióticos, le mueve el entusiasmo con estas palabras: "Publiquen, publiquen. A Cuba por todos los agujeros. Las guerras van sobre caminos: de papeles".

\section{NO HAY CETRO MEJOR QUE UN BUEN PERIÓDICO}

La vigencia de Martí es asombrosa, y se reconoce por cuantos se han acercado a su obra. Esta vigencia es extraordinaria, y no muy frecuente. Pasada su época, casi siempre el mensaje de los escritores se debilita. En Martí sucede todo lo contrario: como previó y creó para ef futuro, es cada vez mayor la actualidad de su pensamiento. No hay aspecto de sus direcciones, así las fundamentales como las secundarias, en que no tenga validez lo que escribió. Se la empareja con las figuras: más sobresalientes de la cultura hispánica en los últimos años: Sarmiento, Martí, Unamuno, es la trilogía que apunta en los juicios de hombres tan ponderados como don Federico de Onís.

Las ideas de Martí sobre el periodismo comportan una actualidad casi dolorosa. Como tuvo tan elevado concepto de la función periodística, esa vigencia crece, en razón misma de la gran crisis por la que atraviesa. la prensa en nuestra época, muy especialmente en nuestra América.

La misión de la prensa la fija en un párrafo bien conocido, pero. que no podemos omitir, porque conviene siempre volver a esa fuente de maravillosa transparencia. El dijo: "No es el oficio de la prensa pe- 
riódica informar ligera y frívolamente sobre los hechos que acaecen, o censurarlos con mayor suma de afecto o de adhesión. Toca a la prensa encaminar, explicar, enseñar, guiar, dirigir; tócale examinar los conflictos, no irritarlos con un juicio apasionado; no encarnizarlos con un alarde de adhesión tal vez extemporánea; tócale proponer soluciones, madurarlas y hacerlas fáciles, someterlas a consulta y reformarlas según ellas; tócale, en fin, establecer y fundamentar enseñanzas, si pretende que el país la respete, y que conforme a sus servicios y merecimientos, la proteja y la honre".

"Tiene la prensa periódica altísimas misiones: es la una explicar en la paz... La prensa no es aprobación bondadosa $o$ ira insultante; es proposiciones, estudio, examen y consejo".

Muchos otros juicios de Martí podrían citarse, todos corroborando su criterio sobre la superior misión de la prensa. "La prensa no puede ser, en estos tiempos de creación, mero vehículo de noticias, ni mera sierva de intereses, ni mero desahogo de la exuberante y hojosa imaginación".

Pero podemos entresacar también numerosos pensamientos dirigidos a la misión del periodista. Se refiere a la manera en que debe escribirse, y dice: "Que un periódico sea literario no depende de que se vierta en él mucha literatura, sino de que se escriba literariamente todo".

Para periódicos y periodistas, esta norma tan necesaria de poner en práctica en estos tiempos nuestros: "Debe desobedecer los apetitos del bien personal, y atender imparcialmente el bien público".

LO SUBLIME ES LA ESENCIA DE LA VIDA: LA MONTAÑA REMATA EN PICO; LO SUBLIME ES COMO PICO DE MONTAÑA

Al término de estas incursiones, ligeras y desordenadas, por las huellas periodísticas de Martí, nos volvemos al punto de partida. Con todo y ser un periodista excepcional, seguimos creyendo que alcanzó tal tamaño, porque estuvo más alto aún: porque fue un gran escritor, impulsado por una vocación superior a todas. La vocación apostólica.

Cuando se habla de Martí como de gran periodista, nos parece que queda algo por decir, porque ser gran periodista fue poco para su enorme significación como escritor. Volvemos a decirlo: el periodismo nos parece una manera, una técnica, en tanto que el escritor es un don. Además, entra en esto un poco la concepción cada vez más pobre y de molde, 
que del periodismo vamos teniendo: una labor que requiere conocimientos y habilidad, travesura e ingenio, pero a la que casi siempre sobra el pensamiento por cuenta propia. Y aquí está el punto básico de nuestro criterio. Cierto que en su tiempo el periodismo era más de ideas que de noticias, más de pensamiento que de hechos. Era posible entonces que un escritor como Martí llenara casi una página de las de entonces - las sábanas de La Nación de Buenos Aires, por ejemplo-con un trabajo dedicado por entero a describir la inauguración de la Estatua de la Libertad o la construcción del Puente de Brooklyn. ¿Qué periódico de nuestra época sería capaz de dar cabida a trabajos como ésos, y como tantos otros, destinados a presentar un acontecimiento de la época, o a reseñar la vida de un personaje que acaba de morir, o a pintar las fiestas y regocijos de una fecha patriótica? Estamos seguros de que, de haber escrito en estos tiempos, sus correspondencias difícilmente hubieran aparecido en ninguno de los periódicos que hoy se publican. $\mathrm{Y}$ tampoco estamos muy seguros de que las revistas hubieran hallado interés en publicar una de sus largas reseñas de la Primera Conferencia Americana, por ejemplo. Fue una suerte que en los periódicos de su tiempo se apreciara una obra que tenía más de literaria que de periodística, aunque él nunca olvidó el interés de los lectores, y puso agilidad y movimiento, color y vida, en sus escritos. Hubo también una circunstancia que no podemos olvidar. Hay muchas formas periodisticas en la obra de Martí. Y la que le da relieve mayor, la que le mantiene su primado de escritor, es la que le sirvió para sus correspondencias.

El periodismo de Martí va más allá de lo que entendemos y admitimos por periodismo. Periodismo lo fue por mandato de su misión. Pero luchó contra las limitaciones que quisieron imponerle quienes, regenteando los periódicos en que escribía, le pedían que escribiera con menos literatura y prodigara en cambio las malas noticias, más del gusto público. Fueron muchos los que quisieron poner limitaciones a su entusiasmo y a su don creador, para compelirlo a los límites estrechos del diarismo corriente. $Y$ con su arte y sus mañas pudo valerse, sin embargo, para hacer una obra perdurable, que de otro modo hubiera sido una de tantas, perdidas en los periódicos de América.

El don del escritor lo vieron Sarmiento y Darío, Vicuña Mackenna y Frederick Lollié, y todos los espíritus superiores de su época, que se mostraron sorprendidos del estilo y las ideas de Martí. Pero los lectores corrientes pasaron seguramente por alto aquella página ennegrecida de tanta letra, lo mismo que hoy vemos que hacen la generalidad de los 
lectores, que pasan sin fijar por ellas la vista, las páginas literarias, para buscar la noticia o el comentario de la actualidad. Sin la gran significación histórica de su vida y la magna importancia de su obra, hoy no se leería a Martí como lo hacemos en todas partes. Pero esa vida y esa. obra han quedado como un faro indestructible señalando rutas a los hombres, y su luz es punto de referencia en el mar de las crisis que conmueven al mundo.

FÉLIX Lizaso.

Miami Beach, Florida. 
